SPECIAL COMMUNICATION

\title{
European Union policy on smokeless tobacco: a statement in favour of evidence based regulation for public health
}

\author{
C Bates, K Fagerström, M J Jarvis, M Kunze, A McNeill, L Ramström
}

Tobacco Control 2003;12:360-367

See end of article for authors' affiliations

Correspondence to: Karl Fagerström, Smokers Information Centre, Fagerström Consulting, Helsingborg, Sweden; karl.fagerstrom@ swipnet.se
Rationale: This statement is an updated version of one released by the same authors in February 2003. The statement was produced to follow up the Royal College of Physicians (RCP) Tobacco Advisory Group report "Protecting smokers, saving lives: the case for a tobacco and nicotine regulatory authority", ' which argued for an evidence based regulatory approach to smokeless tobacco and harm reduction and posed a series of questions that regulators must address in relation to smokeless tobacco.

The purpose of this statement is to provide arguments of fact and principle to follow the RCP's report and to outline the public health case for changing existing European Union (EU) regulation in this area. A review of regulation in relation to harm reduction and regulation of tobacco products other than cigarettes is required in Article 11 of EU directive 2001/37/EC, and this is a contribution towards forming a consensus in the European public health community about what policy the EU should adopt in the light of this review, or following ongoing legal action that may potentially strike out the existing regulation altogether.

Public health case: We believe that the partial ban applied to some forms of smokeless tobacco in the EU should be replaced by regulation of the toxicity of all smokeless tobacco. We hold this view for public health reasons: smokeless tobacco is substantially less harmful than smoking and evidence from Sweden suggests it is used as a substitute for smoking and for smoking cessation. To the extent there is a "gateway" it appears not to lead to smoking, but away from it and is an important reason why Sweden has the lowest rates of tobacco related disease in Europe. We think it is wrong to deny other Europeans this option for risk reduction and that the current ban violates rights of smokers to control their own risks. For smokers that are addicted to nicotine and cannot or will not stop, it is important that they can take advantage of much less hazardous forms of nicotine and tobacco-the alternative being to "quit or die" ${ }^{\prime \prime}$. and many die. While nicotine replacement therapies (NRT) may have a role in harm reduction, tobacco based harm reduction options may reach more smokers and in a different, market based, way. Chewing tobacco is not banned or regulated in the EU but is often highly toxic, and our proposal could remove more products from the market than it permitted.

Regulatory options: We believe that the EU policy on smokeless tobacco should adapt to new scientific knowledge and that the European Commission should bring forward proposals to amend or replace Article 8 of directive 2001/37/EC with a new regulatory framework. Canada has developed testing regimens for tobacco constituents and these could be readily adapted to the European situation. A review of EU policy in this area is required no later than December 2004, and we believe the Commission should expedite the part of its review that deals with harm reduction and regulation of tobacco products other than cigarettes so as to reconsider its policy on smokeless tobacco. We held this view before Swedish Match brought its legal proceedings to challenge EU legislation and we will continue to hold these views if its action fails.

\section{PUBLIC HEALTH ARGUMENTS}

\section{Purpose of tobacco control}

The ultimate purpose of tobacco control campaigning and organisations should be clearly stated: in our view it is to reduce the burden of disease and death, mostly from cancer, cardiovascular disease (CVD), and lung disease, arising from tobacco use. The aim is not in itself to campaign against tobacco. Because of the dominance of the cigarette market, in most situations those two strategies coincide. However, there may be some situations where they conflict-where this is the case, we give priority to reducing disease. Such a case arises where two conditions are met:

- where the use of a tobacco product is substantially less hazardous than cigarettes

- where that tobacco product may substitute for cigarette use or facilitate increased smoking cessation at individual and population level.
This is the situation with oral tobacco products, such as "snus", a form of oral tobacco widely used in Sweden and to a lesser extent in some other North European countries. New products are also emerging on the US market, which may also be targeted in this way. For this reason, there is a strategic question about how the tobacco control community should respond to such products. This is brought into a sharper focus in the EU because of legal challenges to EU regulation in this area, and a commitment to review policy by the end of 2004. Abbreviations: COPD, chronic obstructive pulmonary disease; CVD,
cardiovascular disease; ECJ, European Court of Justice; EU, European
Union; NRT, nicotine replacement therapy; PP, precautionary principle: RCP, Royal College of Physicians 


\section{Position of addicted smokers}

It is also important that we are realistic about the situation of many tobacco users. Tobacco delivered nicotine is powerfully addictive and many users cannot or will not give up. Though addiction is a type of disease in its own right, the aspiration to tackle both the addiction and the physical harm by complete tobacco cessation may only work for a subset of users. The attempt to tackle both addiction and harm may end in tackling neither. For some-for example, those with certain mental health conditions-there may be therapeutic benefits derived from nicotine or tobacco. For others, it is poverty and the ubiquity of tobacco in their communities that create a powerful barrier to individual cessation. We also know that the strength of addiction (as measured by nicotine intake) can increase with poverty. There are over 1.2 billion tobacco users world wide-increasing at about 80000 per day. In the EU there are almost 100 million smokers, and smoking kills $550000 \mathrm{EU}$ citizens per year. We believe it is essential that every option be considered for reducing this toll. That includes harm reduction and product regulation strategies based on reducing the damage done to people that continue to use tobacco or nicotine for whatever reason.

\section{Harm caused by smokeless tobacco}

Smokeless tobacco is not harmless. For example, smokeless tobacco products used on the Indian subcontinent and some products in the USA cause oral cancer. In India, smokeless tobacco is a major cause of oral cancer. But the evidence shows that any link between smokeless tobacco in the form of Swedish snus and oral cancer is not established. ${ }^{34}$ The largest review, Nilson (1998), ${ }^{5}$ concluded that although:

\section{"...20\% of all grown-up Swedish males use moist snuff, it has not been possible to detect any significant increase in the incidence of cancer of the oral cavity or pharynx - the prevalence of which by international standards remains low in this country."}

There are other health effects that arise in the oral cavitysuch as lesions and gingivitis-and a cancer risk from products other than Swedish snus must be anticipated. Smokeless tobacco may also be associated with CVD, though the evidence is contradictory and far from clear. Asplund, in a review of the evidence, indicated that smokeless tobacco was associated with a much lower risk of adverse cardiovascular effects than smoking ${ }^{6}$ and in a literature review commissioned by $\mathrm{ASH},{ }^{7}$ he concluded:

\section{"Smoking increases the risk of myocardial infarction, sudden death, stroke and peripheral artery disease of the legs by 2-4 times. Whether or not snuff use is associated with an increased risk of myocardial infarction and sudden death is still controversial. If there is an excess risk, it is very much smaller than for smoking. For stroke or peripheral artery disease, there is no scientific information on possible risks of snuff use."}

A subsequent study has found that snuff use is not associated with any apparent excess risk of stroke. ${ }^{8}$ However, for oral tobacco to play a role in harm reduction it is not necessary to show that it does not cause cancer-it just needs to be substantially less hazardous than smoking. Even allowing for cautious assumptions about the health impact, snus-and other oral tobaccos-are a very substantially less dangerous way to use tobacco than cigarettes. Smokeless tobaccos are not associated with major lung diseases, including chronic obstructive pulmonary disease (COPD) and lung cancer, which account for more than half of smoking related deaths in Europe. If there is a CVD risk, which is not yet clear, it appears to be a substantially lower CVD risk than for smoking. Smokeless tobacco also produces no environmental tobacco smoke (ETS) and therefore eliminates an important source of disease in non-smokers and children. These are very substantial benefits in reduced risk to anyone that switches from smoking to smokeless tobacco, and we believe the public health community has a moral obligation to explore this strategy. It is likewise ethically wrong to actively deny users the option to reduce their risk in this way.

\section{Addictiveness and nicotine delivery}

Smokeless tobacco use is an effective delivery system for nicotine and is therefore addictive. Addictiveness is in itself a bad characteristic compared to not using the product at all. However, it is the nicotine delivery characteristics of smokeless tobacco that make it both addictive and a viable alternative to cigarette use for many users-it is capable of delivering a satisfactory nicotine dose. Smokeless tobacco use does not match the arterial nicotine "bolus" (sharp spike) delivered by smoking, but still creates a peak venous bloodnicotine level that exceeds all NRT products (including the nasal spray) and is similar to smoking. The fact that it more closely matches the nicotine delivery profile of smoking may be one reason why users find it more effective that NRT as an alternative to smoking.

\section{Risks to users}

The risk to the user arising from use of a smokeless tobacco product varies by product and is to some extent uncertainnotably in the area of heart disease (though at worst the heart disease impact appears to be substantially less than smoking). However, we are confident that the evidence base described above and elsewhere ${ }^{9}$ suggests that it is reasonable to formulate the overall relative risk as follows: on average Scandinavian or some American smokeless tobaccos are at least 90\% less hazardous than cigarette smoking. In a spectrum of risk, snus is much closer to NRT than it is to cigarette smoking. Further, the actual risk can be controlled through regulation-for example, by setting maximum thresholds for specific carcinogens or other toxins such as heavy metals. These data were not readily available at the time the ban was originally implemented in the early 1990s and therefore justify consideration of a change of approach in response to new knowledge.

\section{Risks associated with banning smokeless tobacco}

It might be argued that removing a ban on a product with known dangers, however low, can only increase risks. This is not the case because bans on smokeless tobacco also carry risks. It is quite possible that a ban on smokeless tobacco would mean more tobacco users use cigarettes because the opportunities to switch to or start on smokeless tobacco are denied. To the extent that the ban promotes cigarette use, it carries risks. There is no evidence to show that the status quo in EU policy represents an optimum public health outcome or that the policy does not increase tobacco related harm.

\section{Evidence from Sweden}

Evidence from Sweden suggests snus plays a positive public health role as a substitute for smoking and as an aid to smoking cessation. It is impossible to be definitive about this, because it is impossible to run a controlled trial on a whole nation. However, consider the following:

- Sweden has the lowest levels of tobacco related mortality in the developed world by some distance-approximately half the tobacco related mortality of the rest of the EU. ${ }^{10}$ 
- Sweden has the lowest male smoking prevalence in Europe (15\% daily) and low female (around 20\%) prevalence (adults 18-70 years old in 2002).

- However, it has comparable male tobacco prevalence and total consumption to neighbours Norway and Denmarksuggesting the big difference is in the type of tobacco used, rather than overall propensity to use tobacco or consume nicotine.

- About half of tobacco in Sweden is now consumed as snus-this share has steadily grown since the 1970s.

- A study of current and former smokers 25-55 years old found that $33 \%$ of ex-smokers report use of snus-almost twice the number that report use of a pharmaceutical treatment (17\%). ${ }^{11}$ A large nationwide representative study found that among males who have used a single aid to stop daily smoking, and succeeded in doing so, some $70 \%$ had used snus and some $30 \%$ had used some kind of NRT. ${ }^{12}$

- There are far more ex-smokers among snus users, than exsnus users among smokers-a substantial population study has been conducted by Ramstrom with funding from the National Institute of Public Health in Sweden; the data has been presented at conferences and is in the public domain, though not yet published. ${ }^{12}$ A published study by Rodu also showed similar results. ${ }^{13}$

- It is possible-though difficult to test-that snus use has contributed to "denormalisation" of smoking and to the unacceptability of ETS. This may be a factor in low rates of smoking among women (who do not use snus very much) and acceptability of smoke-free places.

Reasons for low rates of tobacco mortality in Sweden An important explanation for the low rates of tobacco related mortality in Sweden is the contribution made by the high use of smokeless tobacco. It is difficult to conclude anything other than a positive public health role for snus in Sweden, though there remains doubt over the magnitude of the effect. There are no other convincing explanations for low smoking prevalence in Sweden, combined with relative high tobacco use. The population data from Sweden are much clearer now than when the ban was introduced and again justify a reconsideration of policy at the European level.

\section{Human and consumer rights}

There is an emerging literature on the "human rights" dimension to this problem, stressing the right of smokers to good information and the choice of risk reduction strategies. $^{14}{ }^{15}$ Through the ban, the EU is actively preventing smokers having access to a product at least $90 \%$ less dangerous than cigarettes, but that is clearly an effective substitute for at least some people (and for many people in Sweden). It is important to consider where the EU draws its moral (and legal) authority to make such "life-or-death" choices on behalf of its citizens-especially as, on the basis of Swedish evidence, it appears to be making the wrong choices.

\section{How would smokeless tobacco be used outside Sweden?}

There is legitimate doubt about whether snus or similar products would be used in the same way in other member states as in Sweden, or to the same extent. However, that is unknowable in advance and the ban explicitly rules it out. By banning we know how it will be used-either not at all, or on a black market. We cannot really know what would happen until it is available, marketed, and a suitable regulatory regime and tax structure in place-these are all variables that would affect its use. What we do know is that it has the potential to be used to reduce harm. If it looked as though there was an emerging overall negative impact (unlikely in our view) policy drivers such as taxation and modifications of the product standards could be used to trim demand. Even if a small number-relative to Sweden-used it, there may still be a considerable public health gain. An important area for further research is how consumers might respond to the introduction of new tobacco products that are positioned as less hazardous than cigarettes.

\section{Gateway effects}

There is concern that smokeless tobacco will function as a lead-in to smoking for people who would not otherwise smoke. Such "gateway effects" are always contentious, and they are hard to demonstrate for the simple reason that we do not know what smokeless users would have done in the absence of smokeless tobacco-they may have simply moved straight to smoking. Gateways can act in the opposite direction too-they can be "exits" rather than "entrances". Smokers may move to smokeless tobacco or use smokeless tobacco to quit, where they would otherwise have continued to smoke. Starters on smokeless tobacco may continue as smokeless users but otherwise have started with cigarettes, so that smokeless tobacco is a diversion from smoking. In both the USA and Sweden, most smokeless tobacco use cannot be a gateway to smoking, either because smokeless users never started smoking or because they started smoking first. For the minority who started using smokeless before cigarettes they may or may not have had their smoking caused by smokeless use.

\section{Exit or entrance gateway}

Understanding the order in which tobacco users take up different products is an important and necessary factor in establishing a gateway effect and whether the gateway is an exit from or entrance to smoking, but it is not in itself sufficient to establish a gateway from smokeless to cigarettes. The basic problem is that it is difficult to know whether those that start with smokeless tobacco would otherwise have started on cigarettes in the absence of smokeless tobacco. The data from Sweden suggest that the gateway is more likely to be an "exit" from smoking rather than an "entrance". Among Swedish males with a primary use of snus no more than $20 \%$ ever started smoking, while $45 \%$ of other males did become smokers. ${ }^{12}$ In addition to this compelling evidence from the pattern of transitions, Sweden has the lowest rate of male smoking in Europe, combined with high levels of snus use. There is no other credible explanation for such low male smoking prevalence than the displacement and cessation of smoking through smokeless tobacco use. In total therefore, the Swedish data suggest that uptake of snus use prevents rather than promotes smoking and therefore contributes a net public health benefit. There have been studies in the USA that claim to show a gateway effect from smokeless tobacco use to smoking for a minority of smokeless users. ${ }^{16}$ However, these studies or related commentary have generally drawn causal inferences based on observation of transitions between often poorly defined categories of tobacco use, and sometimes from groups that are unrepresentative of the general population, such as the military. Psychosocial predictors of smoking initiation (school performance, parental smoking, risk taking, etc) can be used to assess which smokeless tobacco users might otherwise have been smokers. When these confounding factors are taken into account, the data do not show that initial smokeless tobacco use adds to the propensity to become a smoker. ${ }^{17}{ }^{18}$

\section{Unintended population effects}

There are numerous other potential population effects under discussion: will there be reduced cessation, increased relapse, 
wider use, etc? Though some of these ideas are plausible, all such theories are at present contentious and with minimal or no supporting evidence. To take one example: does smokeless undermine the propensity to quit smoking by helping smokers survive the discomfort of smokefree policies? For snus to be shown to be dissipating the pressure to quit caused by smokefree policies (and therefore have a negative impact on public health) we would need to assess the following contributory factors:

- How much combined daily snus and smoking use is there? (Only 2\% among men in Sweden compared to $19 \%$ with snus as their only daily tobacco use)..$^{12}$ If the combined use is not daily, it is unlikely to be used in overcoming smokefree restrictions.

- How much does smokefree contribute to smoking cessation? There is clearly an effect. One estimate suggests that completely smokefree workplaces in the UK would reduce consumption by $8 \%$. This is one of the most important tobacco control measures, but it is still only one factor of many (price, health, media campaigns, etc) in causing smokers to quit.

- How much would availability of smokeless tobacco reduce (or increase) likelihood of quitting due to smokefree places? (Note: the magnitude and sign of this effect is unknown). Some assume that it is withdrawal that drives smoking cessation arising from smokefree areas and therefore smokeless tobacco would remove the pressure to quit created by repeated temporary withdrawal. However, it could easily be "denormalisation" of smoke due to reduced smoke. In which case smokeless might contribute to cessation.

- Is it right to deny people products so that they are forced to feel discomfort in smokefree areas because this makes them more likely to quit? This ethical point is important.

\section{Role of surveillance}

In general we believe there is too little surveillance of the tobacco market and its impacts on health in Europe. In a comprehensive surveillance regime, any adverse trends that developed in the use of smokeless tobacco or other tobacco products could be detected and addressed with new regulation-such as taxation, marketing restrictions, labelling, or product standards. Note that it is impossible to be absolutely certain about the outcome of a change in policy on smokeless tobacco, just as it is impossible to be certain that not changing policy is the best course. However, a surveillance regimen would create some safeguards.

\section{Should the "precautionary principle" apply?}

Some have argued that because there is not complete knowledge of how smokeless tobacco would be used or all its health effects, we should invoke the precautionary principle (PP) and keep it banned until there is a complete evidence base. Though this sounds reasonable at first take, it is actually a misuse of the PP. The PP is designed for use where there is some concern that a human activity is causing damage (usually to the environment) and scientific uncertainty about whether it is happening or the magnitude of the effect might otherwise be used as a reason not to act to mitigate or control the activity. The PP usually challenges those defending the status quo with uncertainties about the impact of change. The situation with smokeless tobacco is completely different to those situations where the precautionary principle is typically invoked. It may be that the status quo in tobacco use, the dominance of cigarettes, is causing the most harm and that the ban on oral tobacco is increasing the harm - that would almost certainly be the case if the experience of Sweden was generalised to Europe as a whole. So one can easily see the ban as problematic and invoke the precautionary principle on the basis of what is known about Sweden as a reason to act to remove the ban.

\section{Why not use NRT?}

It is sometimes claimed that anything that can be done with smokeless tobacco in harm reduction terms could equally be done with NRT-and with virtually no risk. This view misunderstands two crucial differences between NRT and smokeless tobacco. The first is the nicotine delivery profilesmokeless tobacco far more closely matches cigarettes ${ }^{19}$ and therefore can more easily be an acceptable substitute for addicted users. The NRT nasal spray comes close but this is difficult to use and not popular. There may be other tobacco related sensory effects that are important and not present in NRT. The success of any harm reduction strategy would depend on the numbers of people that made a switch-and that in turn would depend on the consumer acceptability of the product. The second difference is the position of smokeless tobacco in a market place: smokeless tobacco would be occupying a different cultural space. Switching to smokeless tobacco is not a "medical intervention", rather it is what concerned smokers may do as a way of changing their tobacco use.

\section{Characterising the two sides of the debate}

Many health advocates are uncomfortable with the concept that a certain class of tobacco products could play a role in a health strategy and fear that such strategies may be divisive. They characterise the debate as "pro-snus" versus "antisnus". However, there is a substantial body of informed and independent opinion that sees the value of harm reduction strategies based on smokeless tobacco. For them the debate is not "pro-snus versus anti-snus", rather they would frame it as "a smoker's right to options for harm reduction" versus "health professional's authoritarian insistence that the only valid choice for smokers is to quit or die as an addicted cigarette user" —or to shorten this: "harm reduction" versus "quit or die". In practice there is a spectrum of views about the evidence and how to act in the face of uncertainties.

\section{Pro- or anti-tobacco industry}

Both sides claim they are taking an anti-tobacco industry stance. The "quit or die" grouping simply asserts that smokeless tobacco is made by the tobacco industry. The "harm reduction" side recognises that the tobacco industry is heterogeneous and developing all the time. They believe that smokeless tobacco is a viable competitor to the hegemony of the cigarette makers, that it will disrupt the market and usher in new forms of regulations that the biggest tobacco companies will be hard pressed to satisfy with their conventional cigarette designs. The "harm reduction" grouping sees the "quit or die" grouping as unwitting and naïve allies of Big Tobacco-Philip Morris and British American Tobacco-cigarette companies that do not make smokeless tobacco.

\section{Fear of repeating the "lights" mistake}

The most promising approach to harm reduction in the last century was identified as reducing tar yields. This policy was based on machine tests of tar yield which were misleading as they ignored the nicotine compensating behaviour of smokers. Industry documents reveal how this was exploited, as the industry knew that although machine tested yields were reduced, smokers would alter their smoking patterns to maintain nicotine levels and hence also the extent of toxin exposure. ${ }^{20}$ Yet the industry marketed the products in ways that implied harm reduction and many smokers believed the 
cigarettes were less harmful than regular cigarettes. ${ }^{21} 22$ On this occasion there was no reduction in harm and smokers were misled by the industry which provided false reassurance. Some tobacco control advocates are afraid of repeating this mistake with smokeless tobacco, but the situation here is different. With smokeless tobaccos like snus, there is a substantial reduction in harm compared with smoking cigarettes, since nicotine exposure is no higher and there is no exposure at all to the combustion products in tobacco smoke-that is, the smoke constituents known to be the most harmful ones. Yet it is the public health community which is in danger of misleading consumers by pretending there is no difference in risk or banning the product. For example, the following quotes were made in June 2003 by the US Surgeon General before a Congressional Committee:23

"No matter what you may hear today or read in press reports later, I cannot conclude that the use of any tobacco product is a safer alternative to smoking", and

"There is no significant scientific evidence that suggests smokeless tobacco is a safer alternative to cigarettes".

\section{REGULATION OF SMOKELESS TOBACCO IN EUROPE AND THE LEGAL CHALLENGE \\ Regulation of smokeless tobacco in the EU}

Smokeless tobacco in the EU is now regulated under directive 2001/37/EC ${ }^{2}$. This retains provisions originally introduced in directive $92 / 41 /$ EEC. Under its treaty of accession, Sweden is exempted from this ban and this exemption is reflected in the directive as below. The 2001 directive states:

Article 2.4. "tobacco for oral use" means all products for oral use, except those intended to be smoked or chewed, made wholly or partly of tobacco, in powder or in particulate form or in any combination of those forms, particularly those presented in sachet portions or porous sachets, or in a form resembling a food product.

Article 8. Member States shall prohibit the placing on the market of tobacco for oral use, without prejudice to [the exemption granted for Sweden].

\section{Legal challenges}

This position is now facing two legal challenges-from a German tobacco distributor backed by Swedish Match, and by Swedish Match directly through a judicial review of the UK government's implementation of these directives that will be referred to the European Court of Justice. The case made by Swedish Match argues the EU's actions are unlawful, unreasonable, unfair, unjustified, disproportionate, and arbitrary, as follows:

- Inadequate legal base because the ban is a public health measure with no single market justification.

- Total prohibition is disproportionate to achieving single market or public health aims. It draws on the case of the advertising directive ${ }^{24}$ in which a complete ban was imposed as a single market measure. The successful defence of 2001/37/EC ${ }^{25}$ was in part because this regulated but does not prohibit trade.

- The ban is arbitrary and discriminatory as it does not include chewing tobacco.

- No reasons have been given for the ban and this breaches a general duty in breach of Article $253^{26}$ of the treaty.

- The ban violates the company's property rights under the European Convention on Human Rights and European Charter of Fundamental Rights of the EU.
- The ban violates the EU treaty provisions on free movement of goods ${ }^{27}$

- The EU has not considered new scientific evidence.

\section{Has Swedish Match got a case?}

We believe the regulation of smokeless tobacco products in the EU is arbitrary and disproportionate, and impossible to justify as a single market measure or a health measure. The current regulation is absurd, as it applies a complete ban to oral tobacco products that are sucked, but no ban or even regulation to oral tobacco products that are chewed. Only meaningless regulation is applied to smoked tobacco as long as they are cigarettes, and no regulation to cigars or handrolling tobacco. It is impossible to justify the logic applying polar extremes of regulation to different products depending on what the user does with it once it is placed in the mouth (no regulation if you chew, complete ban if you suck). It is arbitrary and disproportionate because it does not prohibit cigarettes, which are substantially more toxic (at least 10 times more toxic) than snus.

\section{Burden of proof regarding health claims}

Although we make a case based on public health benefits above, showing a positive public health impact beyond reasonable doubt would not be the issue in the European Court of Justice (ECJ). The burden of proof would be on the EU to show that there was a case for a ban by showing an additional health impact. The directive 2001/37/EC also acknowledges a lower risk for smokeless tobacco products by requiring weaker warnings than for cigarettes (Article 5.4 of 2001/37/EC), in those situations where smokeless tobacco is permitted in the EU, and a weaker warning than was required in the previous directive.

\section{What would happen instead of a ban?}

We believe that the ban should be replaced by regulation. This is an opportunity to shape the smokeless tobacco market and ensure that if such products are used, they are placed on the market with a high level of protection for human health and the consumer, and to ensure that the worst products are either removed from the market or do not come in. Regulation should apply to all smokeless tobacco, including chewing tobaccos that are currently allowed on the market unregulated. It could also apply to the tobacco intended for smoking. The highly toxic chewing tobaccos available in India are actually permitted in the EU at present, whereas much less dangerous products like snus are banned. A rational regulatory approach would reverse this situation, and effectively ban the most toxic smokeless tobacco products.

\section{What regulatory standards could be used?}

A regulatory approach could involve setting maximum standards for a range of target toxins implicated in the main tobacco related diseases. The Canadian government has introduced legislation implementing a measuring and disclosure regimen for all tobacco products, ${ }^{28}$ including smokeless, and this requires extensive testing of tobacco product constituents. The methodologies available for measuring tobacco constituents are listed in the appendix. Note that these measurements are also required for smoking tobacco as well as smokeless tobacco. Such standards could be adapted for Europe by the European Committee for Standardisation (CEN-Comité Européen de Normalisation) and used in EU regulation.

\section{Other standards issues}

Other approaches to a standard might relate the proportion of toxins to the quantity of active drug nicotine and might also 
regulate additives. Some of the contaminants also change with age of the product - and shelf life restrictions might be also imposed. It would require products to be tested to an agreed methodology. In addition, it would be necessary for health claims to be subject to some sort of official scrutiny and backed by evidence-or for EU approved information to be specified for packaging. Such standards could also be applied to smoking tobacco-cigarettes, cigars, pipe and hand-rolling tobacco-on the basis that there is no reason to allow tobacco to be placed on the market that is more toxic simply because the intention is to burn and multiply the toxicity considerably.

\section{Example of a standard}

Voluntary, market based, toxicity standards do exist. For example, table 1 shows the Gothiatek standard (used by Swedish Match). ${ }^{29}$

\section{Impact of regulation}

The Gothiatek standard is quite exacting, and would rule out most products on the market-it might be possible to taper its introduction to allow time for adjustment of growing, manufacturing, and curing processes. If this standard were applied to all smokeless tobacco products, it could take more tobacco products off the market in the EU than it allows on. Some of these products may have high levels of TSNA, but are not regulated or tested at all-simply (and absurdly) because they are intended to be chewed. If applied to smoking tobacco too, it could cause disruption for the cigarette industry, and begin reducing toxins in all tobacco.

\section{Problems of regulation}

The main problems with regulation would be the burdens of testing and verification. However, these should fall on manufacturers-as is the case with cigarettes. For small manufacturers-for example, firms exporting from the Indian subcontinent - the application of any standards would be a barrier to trade, but one that could be justified on health grounds. There is a problem with an absence of ISO standards for measuring toxic constituents for smokeless tobacco, though the measuring techniques are simple and readily available. However, measuring standards do exist for the main toxic constituents in tobacco and are in use in Canada-see appendix.

\section{European Commission review of policy will happen anyway}

The European Commission is required to revisit policy on smokeless tobacco in its review of the effectiveness of 2001/ 37/EC under article 11 of that directive. The Commission is required to review the directive "in the light of developments in

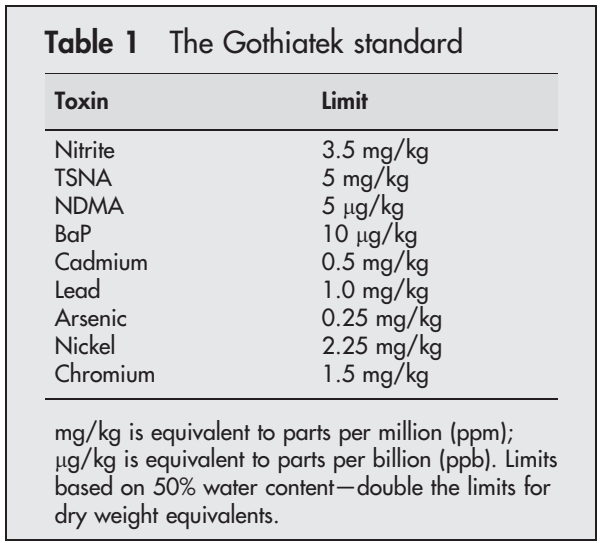

scientific and technical knowledge" with special heed to several important regulatory issues which include:

\section{- tobacco products which may have the potential to reduce harm}

- development of standards concerning products other than cigarettes...

Furthermore, the European Commission should take proper scientific advice so that it can produce evidence based proposals:

...the Commission shall be assisted by scientific and technical experts in order to have all the necessary information available

The review should also include legislative proposals as necessary.

That report shall be accompanied by any proposals for amendments to this Directive which the Commission deems necessary to adapt it to developments in the field of tobacco products...

\section{Is the EU's current position based on scientific advice?}

To our knowledge, the EU did not revisit the scientific advice for Article 8 in the 2001 directive-though much new data had become available. The Commission relied on advice from its Cancer Experts Committee to underpin much of the 2001 directive, but this committee did not give a view on smokeless tobacco. ${ }^{30}$ This is important because the ECJ does not usually see its role as judging scientific advice, but if there is no scientific argument backing the ban then it will prove less of an obstacle to Swedish Match in the ECJ. Part of its case is that the EU provided no reasons for its ban and the recitals to the 2001 directive simply refer to the existing practice. In support of its case, it is quite possible that Swedish Match could call witnesses from the tobacco control community.

\section{Next steps - begin the review}

It would make sense to expedite the review under Article 11 as it applies to smokeless tobacco and convene the necessary experts to give advice. The Commission can either conclude that the policy is sound, in which case it will have built its evidence base for defending the action in the ECJ, if it proceeds to a full hearing. It could also decide that its policy needs to change, in which case it could introduce a legislative proposal. That may avoid a potentially wasteful legal process and is more likely to create a policy that works for public health. An adverse ECJ ruling may also establish principles that constrain the Commission and limit its options for regulation of smokeless tobacco. The Commission (and member states) will have to do the work to defend the case in the ECJ anyway, and we believe that longer term policy on smokeless tobacco will be formed during this period rather than in whatever formal consultation process is established for the review under Article 11-probably in 2004.

\section{Public health community}

We hope that this paper will stimulate debate and thinking within the public health community and that over time we can come to a consensus on the way ahead. We urge a thorough examination of the evidence and arguments, and a determined focus on reducing disease. This is both a scientific 


\section{What this paper adds}

Smokeless tobacco is not harmless. However, some products, in particular the Swedish smokeless tobacco, snus, are considerably less harmful than others. Current EU regulation bans snus, but permits the marketing of chewing tobacco. The highly toxic varieties which exist in India are thereby allowed on the European market.

Toxicological and epidemiological data indicate that snus and some US smokeless tobacco products are at least $90 \%$ less hazardous than cigarette smoking. The limited actual risks can be further controlled through the setting of regulatory standards for specific carcinogens and other toxins. Data also indicate that in Sweden the high use of snus has contributed to a low prevalence of cigarette smoking in men, and so has made an important contribution to the low rates of Swedish tobacco related mortality. We argue that the ban on some of the least harmful forms of smokeless tobacco throughout the EU should be replaced by a regulatory framework applying to all smokeless tobacco products and focusing on eliminating those that are most harmful.

and ethical issue and where there is uncertainty we are obliged to use judgement informed by evidence. Though there is an understandable reluctance to see any kind of ban reversed, it is important that we give primacy to the health of smokers, many in difficult circumstances and heavily addicted to nicotine, and this may involve us in some uncomfortable choices. All the authors of this statement approach the subject with an open mind and are receptive to any arguments and evidence-we hope others will take a similar approach.

\section{CONCLUSION}

\section{Benefits of proposed approach}

We support the replacement of the ban on oral tobacco with an approach that regulates the toxicity of all smokeless (and smoking) tobacco products. Our approach has the following advantages:

- It would create a legally defensible, fair and rational policy - in which public health is given primacy consistent within the framework of EU law.

- It could create public health benefits through smoking cessation and smoking substitution.

- It gives smokers an extra strategy for controlling their risk and eliminating environmental tobacco smoke risk, and thereby respects their consumer and human rights.

- It would apply toxicity controls to the currently unregulated chewing products such as gutkha and paan available in the EU and currently unregulated.

- It could have benefits beyond Europe if a good regulatory model is developed for controlling toxicity of smokeless tobacco-for example, by establishing regulatory norms in the World Health Organization Framework Convention on Tobacco Control.

- It opens the dominant cigarette makers to competition from tobacco products that do far less harm.

\section{ACKNOWLEDGEMENTS}

None of the authors of this statement receives funds or other support from any part of the tobacco industry or its affiliates. This paper reflects the views of its authors, but does not necessarily reflect the positions of the organisations to which they are affiliated. We would like to thank David Sweanor and Doreen McIntyre for their comments.
Authors' affiliations

C Bates, Action on Smoking and Health (ASH), London, UK

K Fagerström, Smokers Information Centre, Fagerström Consulting, Helsingborg, Sweden

M J Jarvis, Cancer Research UK Health Behaviour Unit, University College London, London, UK

M Kunze, Institute of Social Medicine, University of Vienna, Vienna, Austria

A McNeill, St George's Hospital Medical School, University of London, London, UK

L Ramström, Institute for Tobacco Studies, Stockholm, Sweden

\section{APPENDIX: CANADIAN STANDARDS FOR TESTING TOBACCO CONSTITUENTS SCHEDULE 1}

(Section 1 and subsection 12(3))

Official methods for the collection of data on constituents

Item Constituent

Official method

1 (a) Nicotine; (b) nornicotine; (c) anabasine; (d) myosmine; (e) anatabine

2 Ammonia

Official method T-301

Determination of alkaloids in whole tobacco

Official method T-302,

Determination of ammonia in whole tobacco

3 (a) Glycerol; (b) propylene glycol; Official method T-304, (c) triethylene glycol

Determination of humectants in whole tobacco

4. (a) Nickel; (b) lead; (c) cadmium; (d) chromium; (e) arsenic; (f) selenium; (g) mercury

Official method T-306,

Determination of $\mathrm{Ni}, \mathrm{Pb}, \mathrm{Cd}$,

$\mathrm{Cr}, \mathrm{As}$, Se and $\mathrm{Hg}$ in whole tobacco

5. Benzo[a]pyrene

Official method T-307,

Determination of

benzo[a]pyrene in whole

tobacco

$6 \quad$ Nitrate

Official method T-308,

Determination of nitrate from whole tobacco

7 (a) N-nitrosonornicotine; (b) 4-(N- Official method T-309, nitrosomethylamino)-I-(3-pyridyl)- Determination of nitrosamines 1-butanone; (c) $\mathrm{N}$-nitrosoanatabine; in whole tobacco (d) N-nitrosoanabasine

8 Triacetin

Official method T-311, Determination of triacetin in whole tobacco

9 Sodium propionate

Official method T-312,

Determination of sodium propionate in whole tobacco

10 Sorbic acid

Official method T-313, Determination of sorbic acid in whole tobacco

11 Eugenol [2-methoxy-4-(2 propenyl)-phenol]

Official method T-314,

Determination of eugenol in whole tobacco

\section{REFERENCES}

1 Royal College of Physicians. Protecting smokers, saving lives: the case for a tobacco and nicotine regulatory authority. London, 2002.

2 Directive 2001/37/EC Official Journal L 194, 18/07/2001:0026-0035 [EURLEX].

3 Schildt E-B, Eriksson M, Hardell L, et al. Oral snuff, smoking habits and alcohol consumption in relation to oral cancer in a Swedish case-control study. Int J Cancer 1998;77:341-6.

4 Lewin F, Norell SE, Johansson H, et al. Smoking tobacco, oral snuff, and alcohol in the etiology of squamous cell carcinoma of the head and neck. A population-based case-referent study in Sweden. Cancer 1998;82:1367-75.

5 Nilsson R. A qualitative and quantitative risk assessment of snuff dipping. Regul Toxicol Pharmacol 1998;28:1-16.

6 Asplund K. Smokeless tobacco and cardiovascular disease. Prog Cardiovasc Dis 2003;45:383-94.

7 Asplund K. Snuffing, smoking and the risk for heart disease and other vascular diseases. Department of Medicine, University Hospital, Umeå, Sweden, 2002.

8 Asplund K, Nasic S, Janler U, et al. Smokeless tobacco as a possible risk factor for stroke in men. A nested case-control study. Stroke 2003;34:1754-9. 
9 Accortt NA, Waterbor JW, Beall C, et al. Chronic disease mortality in a cohort of smokeless tobacco users. Am J Epidemiol 2002;156:730-7.

10 Peto R, et al. Mortality from smoking in developed countries 1950-2000. Oxford: Oxford University Press, 1994.

11 TEMO (a public polling institute) 2001. Rökare och Slutare (Smokers and Quitters). Commissioned by the Cancer Society and Pharmacia Corporation. Snus better than nicotine preparations. Published in Svenska Dagbladet (major newspaper) 19 April 2001.

12 Ramstrom L. Patterns of use of Swedish smoke-free tobacco, snus: A gate leading to smoking, or a way to give it up? Abstract from $4^{\text {th }}$ SRNT European Conference, Santander, October 2002. Nicotine \& Tobacco Research 2003;5:268.

13 Rodu B, et al. Impact of smokeless tobacco use on smoking in northern Sweden. J Intern Med 2002;252:398-404.

14 Kozlowski L. Harm reduction, public health, and human rights: smokers have a right to be informed of significant harm reduction options. Nicotine and Tobacco Research 2002;4(4)(suppl 2):55-60.

15 Kozlowski LT. First tell the truth: a dialogue on human rights, deception, and the use of smokeless tobacco as a substitute for cigarettes. Tobacco Control 2003:12:34-6.

16 Tomar SL. Snuff use and smoking in U.S. men: implications for harm reduction. Am J Prev Med 2002;23:143-9.

17 O'Connor RJ, Flaherty BP, Quinto Edwards B, et al. Regular smokeless tobacco use is not a predictor of smoking onset when psychosocial predictors are included in the model. Nicotine and Tobacco Research (in press).

18 O'Connor RJ, Kozlowski LT, Flaherty BP, et al. Most smokeless tobacco use does not cause cigarette smoking: results from the 2000 National Household Study on drug abuse. Addiction (in press).
19 Holm H, Jarvis MJ, Russell MAH, et al. Nicotine intake and dependence in Swedish snuff takers. Psychopharmacology 1992;108:507-11.

20 Hurt RD, Robertson CR. Prying open the door to the tobacco industry's secrets about nicotine. The Minnesota Tobacco Trial. JAMA 1998:280:1173-81.

21 Evans $\mathrm{N}$, Joossens L. Consumers and the changing cigarette. London: Health Education Authority, 1999

22 Etter JF, Kozlowski LT, Perneger TV. What smokers believe about light and ultralight cigarettes. Prev Med 2003;36:92-8.

23 House Subcommittee on Commerce, Trade, and Consumer Protection, 3 June 2003. http://energycommerce.house.gov/108/Hearings/ 06032003hearing928/Carmonal 476.htm

24 European Court of Justice, Judgement for the Court in Case C-376/98. Available at Case C-376/98.

25 European Court of Justice, Judgement of the Court in Case C-491/01, The Queen and Secretary of State for Health ex parte British American Tobacco Investments and others. 10 December 2002. http://curia.eu.int/jurisp/ cgi-bin/form.pl? lang = en\&Submit $=$ Submit\&docrequire $=$ judgements \&numaff $=\mathrm{C}-491 \% 2 \mathrm{FO1}+\&$ datefs $=$ \&datefe $=$ \&nomusuel $=$ \&domaine $=\&$ mots $=\&$ resmax $=100 \mathrm{e}$

26 European Commission. Treaty establishing the European Community. Part 5. Institutions of the Commission. Article 253

27 European Commission. Treaty establishing the European Community. Chapter 2. Prohibition of quantitative restrictions between Member States. Article 28/ 29.

28 Health Canada. Tobacco Reporting Regulations. June 2000. [Health Canada]

29 Gothiatek Standard. www.gothiatek.com - the full standard available here.

30 Europe Against Cancer Programme High Level Cancer Experts Committee Consensus Conference on Tobacco Helsinki, 2 October 1996 [Europa].

\section{The lighter side}

\section{LA CIGARETTE DU CONDAMNE.-.}

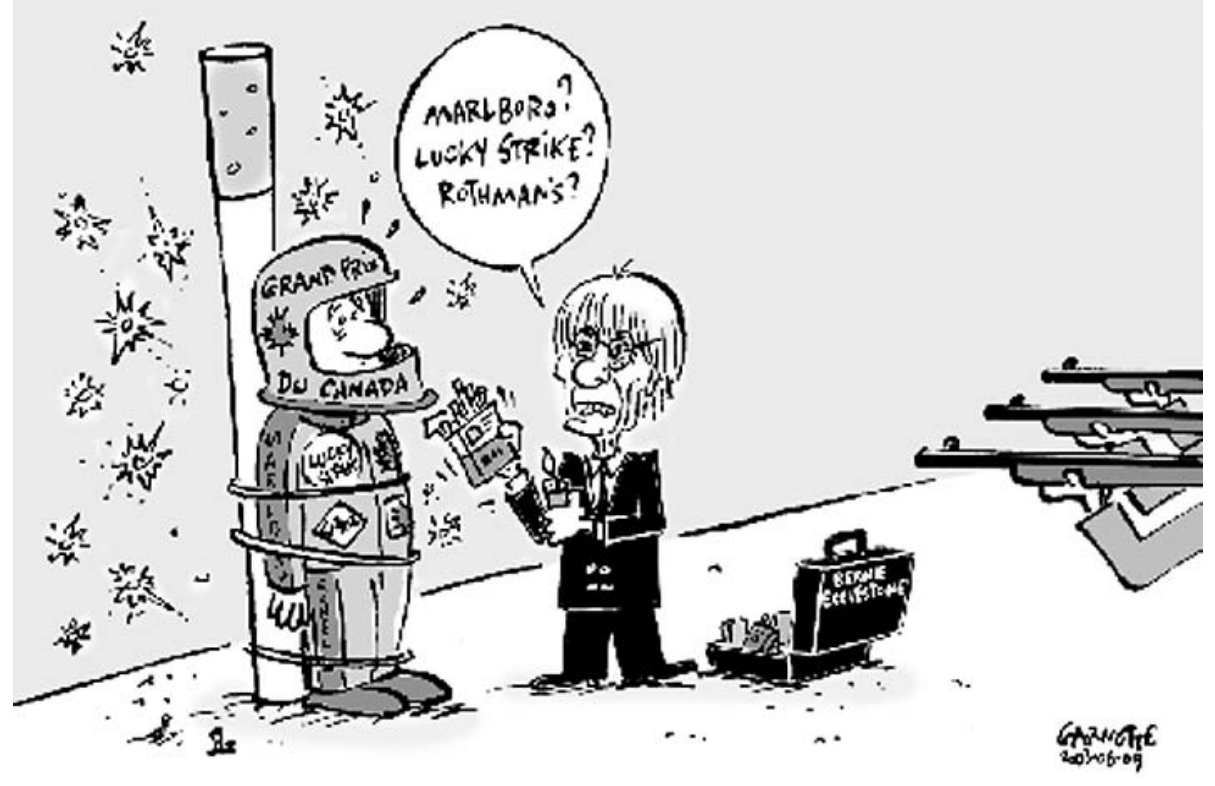

Bernie Ecclestone offers the condemned man his last cigarette. @Garneau, Le Devoir, Montreal, 9 August 2003 